\title{
Studi Kelayakan Pembangunan Tol Pasuruan - Probolinggo
}

\section{The Feasibility Study of Pasuruan - Probolinggo Tollroad}

\author{
Willy Kriswardhana, Nunung Nuring H., Ikhwan Tri Kuncahyo.
}

${ }^{a}$ Staf Pengajar Jurusan Teknik Sipil, Fakultas Teknik, Universitas Jember, Jl. Kalimantan 37 Jember, email: willy.teknik@unej.ac.id

${ }^{\mathrm{b}}$ Staf Pengajar Jurusan Teknik Sipil, Fakultas Teknik, Universitas Jember, Jl. Kalimantan 37 Jember, email: dosen@unej.ac.id

${ }^{c}$ Mahasiswa Jurusan Teknik Sipil, Fakultas Teknik, Universitas Jember, Jl. Kalimantan 37 Jember, email: ikhwankuncahyo07@gmail.com

\begin{abstract}
ABSTRAK
Kabupaten Pasuruan dan Probolinggo adalah salah satu Kabupaten di Jawa Timur yang terkenal dengan pariwisata dan industrinya, seperti gunung bromo dan taman safari. Hal ini membuat Kabupaten Pasuruan mengalami pertumbuhan ekonomi yang cukup signifikan. Untuk memperlancar dan memacu pertumbuhan ekonomi di kedua kabupaten tersebut, pemerintah membangun jalan tol Pasuruan - Probolinggo. Tujuan penulisan penelitian ini adalah untuk menganalisis lalu - lintas jalan eksisting Pasuruan - Probolinggo dan melakukan analisis kelayakan secara finansial. Untuk analisis kelayakan secara finansial ditentukan berdasarkan nilai rasio antara income investor yang didapat dengan biaya pembuatan jalan tol. Nilai kelayakan finansial tersebut berdasarkan analisis Net Present Value (NPV), Benefit Cost Ratio (BCR), Internal Rate of Return (IRR) dan Pay Back Period (PBP). Dalam penelitian ini, nilai DS pada Kecamatan Grati dengan nilai DS rata-rata 0.69 dan pada titik Kecamatan Leces dengan DS rata-rata sebesar 0.60. Secara finansial nilai NPV $>1$, nilai $\mathrm{BCR}>0$ dan nilai IRR $8.3 \%$. Sehingga secara finansial proyek Pembangunan Jalan Tol Pasuruan - Probolinggo layak secara finansial. Arah penelitian selanjutnya telah diberikan pada akhir artikel.
\end{abstract}

Kata kunci: Jalan tol Pasuruan - Probolinggo, Studi Kelayakan

\begin{abstract}
Pasuruan and Probolinggo Regency is a Regency in East Java which is famous for its tourism and industry, such as mount bromo and the safari park. This makes the Pasuruan regency is experiencing significant economic growth. To smoothen and spur economic growth in this area, the government built the Pasuruan Probolinggo toll road. The objective of this study is to analyze the existing road traffic of Pasuruan and Probolinggo and doing the feasibility study. Feasibility study is determined based on the value of the ratio between the income investors gained at the cost of build the toll road. The value of these feasibilitystudy based on the analysis of the Net Present Value (NPV), Benefit Cost Ratio (BCR), Internal Rate of Return (IRR) and the Pay Back Period (PBP). Financially value NPV $>1$, value of BCR $>0$ and the value of the IRR 8.3\%. Toll Road construction project - Probolinggo Pasuruan worth financially and economically. Direction for future research is presented.
\end{abstract}

Keywords: Pasuruan toll road - Probolinggo, Feasibility Study 


\section{PENDAHULUAN}

Perkembangan suatu kota dan wilayah ditentukan atas empat aspek utama yaitu ekonomi, aspek sosial budaya, aspek fisik, dan aspek lingkungan (Widyaningsih,2001). Kabupaten Pasuruan adalah salah satu Kabupaten di Jawa Timur yang terkenal dengan pariwisata dan industrinya, sehingga membuat Kabupaten Pasuruan mengalami pertumbuhan ekonomi yang cukup signifikan, hal ini terlihat dari pertumbuhan PDRB dari kedua kabupaten tersebut.

Pergerakan lalu - lintas dari Probolinggo menuju Pasuruan saat ini dilayani oleh Jalan Pantura yang merupakan jalan arteri primer. Jalan ini secara umum bertipe 4 lajur dua arah, dengan beberapa segmen yang terbagi dan tak terbagi. Perkembangan tata guna lahan sepanjang jalan raya dan hambatan samping adalah fenomena umum di negara berkembang. (Pal \& Roy, 2016). Tata guna lahan pada jalan pantura Probolinggo Pasuruan mempunyai akses langsung menuju jalan. Tata guna lahan yang langsung dapat mengakses jalan menyebabkan banyaknya hambatan samping yang berakibat pada berlurangnya kecepatan dan bertambahnya waktu tempuh. Pada saat kecepatan mulai turun, biaya operasi kendaraan akan meningkat dan waktu untuk melakukan perjalanan akan meningkat. (Stubs, Tayson, \& Dalvi, 1980). Oleh karena itu, pembangunan jalan tol sebagai salah satu alternatif pengurangan waktu tempuh. Salah satu poin di UU no 38 tahun 2004 pasal 43 menerangkan bahwa salah satu fungsi tol adalah meningkatkan hasil guna dan daya guna pelayanan distribusi barang dan jasa guna menunjang peningkatan pertumbuhan ekonomi.

Proyek Jalan Tol Pasuruan - Probolinggo direncanakan sepanjang 31,3 Km dan dibagi menjadi 4 seksi. Tol ini berawal di Desa Grati Tunon, Kecamatan Grati, Pasuruan hingga Desa Sumberkedawung, Kecamatan Leces, Kabupaten Probolinggo. Proyek ini dilaksanakan oleh PT. Waskita Karya (Persero) Tbk. Proyek ini memakan waktu 900 hari kalender dimulai dari 30 Juni 2016.

Sesuai dengan UU No. 38 tahun 2004 tentang Jalan pasal 48 ba bahwa "Tarif tol dihitung berdasarkan kemampuan bayar pengguna jalan, besar keuntungan biaya operasi kendaraan, dan kelayakan investasi”. Maka pembangunan jalan tol Pasuruan - Probolinggo perlu dilakukan analisis kelayakan pembangunanya, agar tidak mengalami kerugian dari biaya yang dikeluarkan untuk membangun. Dalam konteks ini, tujuan penulisan artikel ini adalah untuk memberikan referensi mengenai kelayakan finansial dan ekonomi pada pembangunan jalan tol Pasuruan - Probolinggo. 


\section{METODE PENELITIAN}

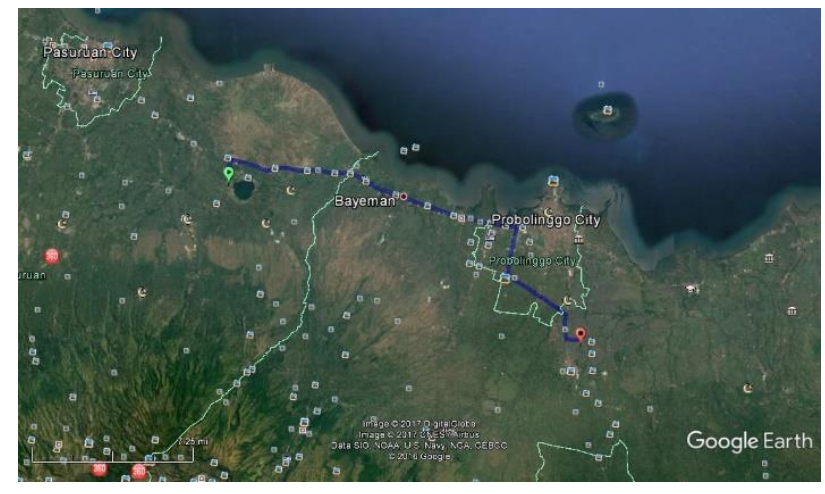

Gambar 1 Lokasi Penelitian

Lokasi penelitian ini berada di Desa Gratitunon, Kecamatan Grati, Kabupaten Pasuruan dan Berakhir di Desa Sumberkedawung, Kecamatan Leces, Kabupaten Probolinggo.

Pengukuran kinerja ruas jalan menggunakan Manual Kapasitas Jalan Indonesia (MKJI) 1997. Proses pemilihan rute (trip assignment) dilakukan guna memperoleh persentase jumlah kendaraan yang melewati tol sebagai pemasukan atau income dari tol tersebut. Untuk outcome atau pengeluaran sendiri terdiri dari biaya pembangunan jalan tol dan perawatan jalan tol.

Langkah selanjutnya adalah perhitungan Biaya Operasi Kendaraan (BOK). BOK dihitung pada jalan pantura eksisting dan jalan tol. Perhitungan ini bertujuan untuk mengetahui besarnya penghematan yang didapatkan apabila pengguna jalan menggunakan jalan tol. Penghematan disini mungkin tidak terlampau dapat dirasakan karena tidak berdampak secara langsung, namun sesungguhnya penghematan mengenai komponen BOK serta nilai waktu seharusnya bisa cukup signifikan.

Penghematan nilai waktu juga dipertimbangkan dalam studi ini. Nilai waktu perjalanan (Value of Travel Time (VTT)) merupakan masukan inti dalam penilaian banyak kebijakan transportasi dan skema infrastruktur yang sering memiliki implikasi ekonomi, sosial dan lingkungan yang substansial. Penghematan nilai waktu umumnya tidak terjadi pada jenis perjalanan yang non-bisnis seperti, sosial, vacation yang biasanya dilakukan pada hari-hari libur. Sedangkan penghematan terhadap biaya operasi kendaraan tetap akan terkadi meskipun hari libur. Namun demikian penghematan biaya operasi kendaraan kemungkinan tidak terjadi pada jam-jam yang off-peak. Nilai waktu dihitung berdasarkan formula Jasa Marga dengan mempertimbangkan studi- studi tentang nilai waktu yang pernah ada. Untuk mengetahui nilai waktu dasar digunakan Formula Herbert Mogring.

Penilaian kelayakan suatu proyek beberapa parameter antara lain Net Present Value (NPV), Benefit Cost Ratio ( BCR), Internal Rate of Return (IRR), dan Pay Back Period (PBP). 


\section{HASIL DAN PEMBAHASAN}

\section{Volume Lalu Lintas}

Dalam penelitian ini terdapat 2 titik survei yakni di Jalan Raya Pantura, Kecamatan Grati Kab. Pasuruan dan Jalan Raya Leces Kab. Probolinggo.

Tabel 3.1 Data hasil traffic counting volume kendaraan (Kend/jam)

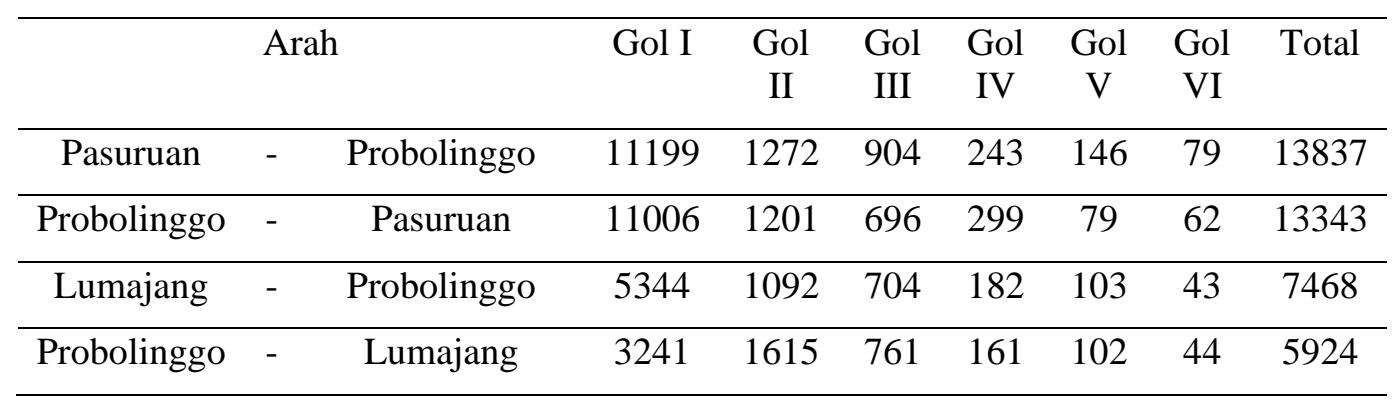

Dari data tersebut diambil volume terbesar yakni pada ruas Grati dengan arah Pasuruan - Probolinggo dan sebaliknya untuk peramalan volume. Peramalan volume kendaraan dihitung dari tahun 2017 - 2038 dengan menggunakan rumus :

$$
F=P(1+i) "
$$

Dimana, $\quad \mathrm{F}=$ Volume kendaraan pada tahun yang diinginkan, $\mathrm{P}=$ Volume pada tahun 2017, $\mathrm{i}=$ Faktor pertumbuhan kendaraan, $\mathrm{n}=$ rentang waktu pertumbuhan (tahun)

\section{Derajat Kejenuhan}

Derajat Kejenuhan dapat dihitung dengan rumus :

$$
\begin{aligned}
& D S=Q / C \\
& D S=0.64
\end{aligned}
$$

Dimana :

$\mathrm{DS}=$ derajat kejenuhan

$\mathrm{Q}=$ arus total lalu lintas $(\mathrm{smp} / \mathrm{jam})=2281.96(\mathrm{smp} / \mathrm{jam})$

$\mathrm{C}=$ kapasitas jalan $(\mathrm{smp} / \mathrm{jam})=1465.2(\mathrm{smp} / \mathrm{jam})$

\section{Kecepatan Arus Bebas}

Kecepatan arus bebas kendaraan ringan dapat dicari dengan menggunakan persamaan :

$$
V_{l v}=\left(F v_{o}+F V_{w}\right) \times F F V_{s f} \times F F V_{r c}
$$

Dimana :

$F V_{l v}=$ kecepatan arus bebas $\mathrm{LV}(\mathrm{km} / \mathrm{jam})=74$

$F v_{o}=$ kecepatan arus bebas dasar $\mathrm{LV}=-4.8$

$F V_{w}=$ Penyesuaian kecepatan akibat lebar jalan $=0.985$

$F F V_{S F}=$ Penyesuaian akibat hambatan samping $=0.97$ 


\section{Pemilihan Rute}

Pemilihan rute (trip assignment) adalah suatu metode untuk mengetahui prosentase kendaraan yang membebani tiap-tiap ruas jalan. Trip assignment dapat dihitung berdasarkan persamaan :

$$
P=50+\frac{50(d+0,5 t)}{((d-50) 2+4,5) 0,5}
$$

Dimana :

$\mathrm{P}=$ Persen Kendaraan yang melewati jalan tol Gempol -Pasuruan.

$\mathrm{d}=$ Jarak yang dihemat bila menggunakan jalan tol Pasuruan - Proboliinggo (mil).

$\mathrm{t}=$ Waktu yang dihemat bila menggunakan jalan tol Pasuruan - Probolinggo.

Contoh Perhitungan Golongan 1 :

Panjang Jalan Eksisting $=37.1 \mathrm{~km}$

Panjang Jalan Tol $\quad=31.3 \mathrm{~km}$

$\mathrm{D} \quad=(37.1 \mathrm{~km}-31.3 \mathrm{~km}) \times 1.6093=9.333394 \mathrm{mil}$

Waktu Tempuh ( Travel Time ) Jalan Eksisting $=33.65$ menit

Waktu Tempuh ( Travel Time) Jalan Tol $\quad 20.63$ menit

$\mathrm{T}($ Koefisien Penghematan Waktu Tempuh ) $=33.65$ menit -20.63 menit $=13.01$ menit

$$
\begin{aligned}
& P=50+\frac{50(9.3394+0,5 \times 13.01)}{((9.3394-50) 2+4,5) 0,5} \\
& P=51.22 \%
\end{aligned}
$$

Jadi volume kendaraan Gol I yang melewati jalan tol Pasuruan - Probolinggo adalah $51.22 \%$ dan sisanya tetap pada jalur eksisting. Perhitungan tersebut dilakukan untuk masing - masing golongan kendaraan sampai tahun 2038.

\section{Analisis Finansial}

Analisis Finansial tol Pasuruan - Probolinggo menggunakan metode NPV, BCR, IRR dan PBP. Tarif yang digunakan pada analisis ini dasar perhitungan adalah tariff tol Gempol - Pandaan sepanjang $13.61 \mathrm{Km}$. Setelah dilakukan interpolasi dengan panjang tol Pasuruan - Probolinggo sepanjang $31.3 \mathrm{~km}$ didapatkan tarif sebesar Gol I = Rp 23.000,-, Gol II=Rp 34.500,-, Gol III= Rp 44.800,-, Gol IV= Rp 56.300,-, Gol V= Rp 67.800,-. Besarnya tarif tol mengalami kenaikan setiap 2 tahun sesuai dengan nilai inflasi rata-rata. Hasil analisis finansial dapat diketahui sebagai berikut :

$$
\begin{aligned}
& \mathrm{NPV}=\mathrm{Rp} 3.714 .790 .824 .834-\mathrm{Rp} 2.925 .435 .384 .457,- \\
& \mathrm{NPV}=\mathrm{Rp} 789.355 .440 .376,-
\end{aligned}
$$




$$
\begin{aligned}
\mathrm{BCR} & =\mathrm{Rp} 3.714 .790 .824 .834,-/ \mathrm{Rp} 2.925 .435 .384 .457,- \\
\mathrm{BCR} & =1.26
\end{aligned}
$$

Karena nilai NPV > 0 dan BCR > 1, maka proyek pembangunan Jalan Tol Pasuruan - Probolinggo dapat dikatakan layak secara finansial. IRR dilakukan dengan cara trial and error sehingga diketahui nilai IRR sebesar $8.32 \%$ dan PBP pada tahun 2030 atau 12,35 tahun setelah peresmian 2018.

\section{Analisis Ekonomi}

Parameter studi kelayakan biasanya menggunakan Benefit Cost Ratio (BCR), Net Present Value (NPV), Internal Rate of Return (IRR), dan Payback Period. Dalam studi ini, parameter yang digunakan adalah BCR dan NPV.

Benefit Cost Ratio (BCR) dihitung menggunakan persamaan berikut:

Total Penghematan BOK= Rp 2.511.808.701.429,-

Total Nilai Waktu $\quad=$ Rp 21.108.819.154,-

Total Biaya Konstruksi = Rp 2.925.435.384.457,-

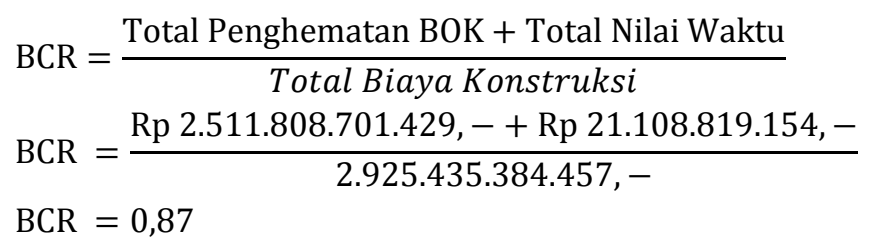

$\mathrm{BCR}<1$, sehingga investasi Proyek Jalan Tol Pasuruan - Probolinggo kurang layak.

Net Present Value (NPV) dihitung menggunakan persamaan berikut:

$\mathrm{NPV}=$ Rp. 2.532.917.520.583 - Rp. 2.925.435.384.457

$=-\operatorname{Rp} 392.517 .863 .874$

NPV $<0$, sehingga investasi Proyek Jalan Tol Pasuruan - Probolinggo kurang layak.

\section{KESIMPULAN}

Dari ananlisis diatas dapat ditarik kesimpulan sebagai berikut :

Berdasarkan analisis kinerja ruas dengan menggunakan metode MKJI

1. 1997 diketahui kondisi kinerja ruas Jalan Raya Pantura, Kec. Grai, Kab. Pasuruan dengan nilai DS rata-rata 0.64 dan pada ruas Jalan Raya Leces, Kec. Leces, Kab. Probolinggo nilai DS rata-rata 0.60.

2. Secara analisis finansial, proyek tol Pasuruan Probolinggo layak, namun secara analisis ekonomi kurang layak. Arti kurang layak dalam hal ini adalah menurut kondisi asumsi saat ini sampai 20 tahun mendatang. Namun perlu diketahui pertumbuhan jumlah kendaraan yang semakin meningkat dapat menyebabkan penghematan yang lebih besar dari segi BOK dan nilai waktu. Perkembangan tata guna lahan di sekitar jalan eksisting juga mempunyai andil dalam perilaku pengguna jalan. Pembangunan yang masif pada sekitar jalan dapat 
menyebabkan peningkatan BOK sehingga pengguna jalan akan lebih berhemat apabila melewati jalan tol.

3. Penelitian selanjutnya dapat mengalisis pemilihan rute lebih mendalam menggunakan model kurva diversi maupun logit biner, sehingga asumsi jumlah kendaraan yang memasuki tol dapat lebih presisi. Penggunaan model BOK yang lain juga dapat diterapkan sebagai perbandingan.

\section{DAFTAR PUSTAKA}

Badan Pusat Statistik. 2017. Kabupaten Probolinggo Dalam Angka. Indonesia: BPS Kabupaten Probolinggo.

Departemen Pekerjaan Umum. 1997. Manual Kapasitas Jalan Indonesia (MKJI). Indonesia: Departemen PU, Dirjen Bina Marga

Fajrinia, Citto Pacama. 2013. Analisis Kelayakan Pembangunan Jalan Tol Gempol Pasuruan. Skripsi. Surabaya. Fakultas Teknik Sipil dan Perencanaan Institut Teknologi Sepuluh November.

Giatman, M. 2006. Ekonomi Teknik. Jakarta: PT. Raja Grafindo Persada.

Pal, Sudipta \& Roy, Sudip Kr. (2016). Impact of Roadside Friction on Travel Speed and LOS of Rural Highways in India. Springer International Publishing. pp. 1-12.

Stubs, P., Tayson, W., \& Dalvi, M. (1980). Transport Economics. London: George Allen and Unwin Ltd.

Widyaningsih, Nikken Setyowati, Relevansi Preferensi Penduduk terhadap Fasilitas Kota yang Mempengaruhi Faktor Perkembangan Kota, Skripsi. Plannit Journal, Th I/No.2 Juli-Agustus 2001. 